\title{
Guías de recomendaciones de prevención de infecciones en pacientes que reciben modificadores de la respuesta biológica
}

\author{
Rosana Jordán ${ }^{1}$, Alejandra Valledor ${ }^{2}$ \\ ${ }^{1}$ Sección Infectología del Hospital Británico de Buenos Aires. ${ }^{2}$ Sección de Infectología del Hospital Italiano de Buenos Aires. \\ Autores y revisores del documento. \\ Consenso de la Sociedad Argentina de Infectología \\ Comisión Directiva de la Sociedad Argentina de Infectología \\ Presidente: Dr. Gustavo Lopardo - Vicepresidente: Dra.Liliana Calanni - Secretario: Dra. Carla Vizzotti - Prosecretario: Dr. Ricardo Teijeiro - \\ Secretario de Actas: Dra. Lucia Daciuk - Tesorero: Dr. Omar Sued - Protesorero: Dr. Lautaro De Vedia - $1^{\circ}$ Vocal Titular: Laura Barcán - \\ $2^{\circ}$ Vocal Titular: Dra. Cristina Miglioranza - $3^{\circ}$ Vocal Titular: Dr. Esteban Nannini - $4^{\circ}$ Vocal Titular: Dr. Jorge Contarelli - $1^{\circ}$ Vocal Suplente: \\ Dra. Teresita Puentes - $2^{\circ}$ Vocal Suplente: Dr. Gustavo Costilla Campero - $3^{\circ}$ Vocal Suplente: Dr. Enrique Raimondo - $4^{\circ}$ Vocal Suplente: \\ Dra. Andrea Vila - Revisores de Cuentas: Dr. Waldo Belloso y Dr. Angel Minguez - Página Web Administración de contenidos: Dr. Javier E. Desse \\ - Secretaria Administrativa: Srta. Alejandra Sayago
}

Comisión de Infecciones en el Paciente Inmunocomprometido

Coordinadora: Dra. Patricia E. Costantini - Secretaria: Dra. Alejandra Valledor Integrantes: Dr. Javier Afeltra, Dr. Aníbal Calmaggi, Dr. José A. Cozzi, Dra. Daniela D’Alessandro, Dra. María Cecilia Dignani, Dra. Carolina Epelbaum, Dra. Graciela Guerrini, Dr. Fabián Herrera, Dra. Rosana Jordán, Dr. Santiago López Papucci, Dra. María Andrea Mónaco, Dra. Andrea Mora, Dra. Andrea Nenna, Dra. Silvina Neyro, Dra. Inés Roccia Rossi, Dra. Claudia Salgueira.

\section{Resumen}

El creciente interés ante el uso de modificadores de la respuesta biológica, en todas las disciplinas, motivó la revisión del tema y la discusión con la comunidad científica analizando el tema. En el presente documento desarrollaremos los agentes más importantes tales como anti-TNF, anti-citoquinas, bloqueadores de la señal coestimulada, bloqueadores de las moléculas de adhesión, bloqueadores de la proliferación de linfocitos, deplecionadores de linfocitos T y B; enfocado a los cuidados, monitoreos, quimioprofilaxis y vacunación necesaria ante cada agente en especial para evitar infecciones en este grupo de pacientes.

Palabras clave: consenso, agentes biológicos, prevención de infecciones.

\section{Abstract}

The growing interest for the use of biological drugs, in all disciplines, led the review of the literature and discussion with the scientific community analyzing this issue. This paper deals with the most important agents such as anti-TNF, anti-cytokines, blockers of the co-stimulated signal, blockers of adhesion molecules, blockers of the proliferation of lymphocytes, agents against $T$ and $B$ lymphocytes. We would focuse on daily care, monitoring, chemoprophylaxis and vaccination required for each particular agent to prevent infections in this group of patients.

Key words: recommendations, biologic agents, prevention of infections.

\section{Correspondencia}

E-mail: alejandra.valledor@hospitalitaliano.org.ar 


\section{Introducción}

Los agentes biológicos han cobrado relevancia en la actualidad debido a su extendido uso en el tratamiento de las enfermedades neoplásicas, trasplantes de órganos sólidos y médula ósea, enfermedades autoinmunes, enfermedades reumatológicas, enfermedad inflamatoria intestinal, entre otras. Es por ello necesario generar guías para tan amplio grupo de especialistas, acerca de las infecciones y dar los lineamientos necesarios para disminuir el riesgo de complicaciones en este grupo de pacientes.

La terapia biológica (también llamada inmunoterapia o terapias inmunomoduladoras, terapia modificadora de la respuesta biológica o bioterapia) utiliza al sistema inmunológico del organismo para combatir una enfermedad determinada, pero esto conlleva inmunosupresión al paciente de intensidad variada según el agente. Es la idea de este trabajo, orientar según el agente usado la profilaxis que se debe usar.

Estos agentes biológicos han mejorado el manejo y el pronóstico de las enfermedades autoinmunes, pero también han aparecido efectos adversos relacionados con su uso, tales como anafilaxia, síndrome de lisis tumoral, tormenta de citoquinas e infecciones. ${ }^{1,2,3,4}$

Existen diferentes agentes biológicos de acuerdo a su mecanismo de acción ${ }^{3}:$ los inhibidores del factor de necrosis tumoral alfa ( $\mathrm{TNF} \alpha$ ), las anti-citoquinas, los bloqueadores de la señal coestimulada, los bloqueadores de las moléculas de adhesión, los bloqueadores de la proliferación de los linfocitos $\mathrm{T}$ activados, agentes neutropenizantes y los deplecionadores de los linfocitos T y B.

\section{INFECCIONES SEGÚN EL BIOLÓGICO}

\section{INHIBIDORES DEL TNF-A (INFLIXIMAB, ADALIMUMAB, ETANERCEPT, GOLIMUMAB Y CERTOLIZUMAB)}

El TNFa es una citoquina que interviene en la respuesta inmunológica normal a las infecciones. Es producida por los linfocitos T, células NK, mastocitos y fagocitos. Este agente aumenta la habilidad de macrófagos de fagocitar micobacterias, produce ácido nítrico en macrófagos que llevan a la muerte de los microorganismos, actúa a nivel del hipotálamo causando fiebre, en el músculo induce catabolismo con pérdida de peso y astenia, induce la síntesis de reactantes de fase aguda en el hígado, estimula el factor estimulante de colonias granulocíticas, produce apoptosis de varias células tumorales, interviene en la formación y man- tenimiento del granuloma y es clave frente a la infección por gérmenes intracelulares.

Al bloquearse su acción por los agentes anti-TNF, la presentación clínica de las infecciones puede ser atípica con ausencia de fiebre. Las infecciones más comunes son: neumonía, artritis séptica y meningitis.

Si bien los estudios randomizados no mostraron incremento de infecciones con el uso de anti-TNF, la vigilancia de postcomercializacion, estudios observacionales y registros de diferentes países mostraron una clara asociación entre infección y el uso de anti-TNF. 1,2,3,4,5,6,8,9,10

El Registro Argentino-BIOBADASAR publicado recientemente mostró un $R R$ de infecciones en pacientes bajo terapia anti-TNF versus no biológicos de 7,87 (IC 95\% $4,7-14)^{11}$ en su primer reporte, y de RR 1,66 (IC 1,38-2,0; $\mathrm{p}<0,05)$ en el reporte más reciente.

Existen factores asociados con mayor riesgo de infección en los pacientes bajo tratamiento con anti-TNF como el uso concomitante de otros inmunosupresores, la actividad de la enfermedad de base y comorbilidades. ${ }^{2,3,4,5}$

El Infliximab es el agente anti-TNF que se asocia con más riesgo de infecciones, debido probablemente a que produce un bloqueo completo del TNF.12,13,14,15 (Tabla 1).

La mayoría de las infecciones han sido reportadas con Infliximab, una de las razones podría ser su mecanismo de acción al bloquear los dos componentes del TNF (celular y soluble) y no uno solo, como en el resto de las drogas del grupo. Veamos cuáles son las infecciones más frecuentemente reportadas:

\section{- Infecciones bacterianas}

Mycobacterium tuberculosis: Tiene una presentación bifásica. Es más frecuente la presentación temprana, que ocurre dentro de los primeros tres meses (reactivación) y una tardía (primoinfección) a partir de los dos años. Se estima que el riesgo de tuberculosis, que en AR es el doble que en la población general, aumenta al doble con el uso de anti-TNF, variando según el agente usado. Globalmente es para todos

\begin{tabular}{|l|c|c|c|c|}
\hline & Infliximab & Adalimumab & Etanercept & Certolizumab \\
\hline $\begin{array}{l}\text { Bloquea TNF } \\
\text { soluble }\end{array}$ & + & - & + & - \\
\hline $\begin{array}{l}\text { Bloquea TNF } \\
\text { membrana }\end{array}$ & + & + & - & + \\
\hline Dosis intervalo & $8-9$ días & $15-19$ días & 4 días & $?$ \\
\hline $\begin{array}{l}\text { Concentración } \\
\text { plasmática }\end{array}$ & $5-8 \mu \mathrm{g} / \mathrm{ml}$ & $5-10 \mu \mathrm{g} / \mathrm{ml}$ & $1-2,4 \mu \mathrm{g} / \mathrm{ml}$ & $0,5-90 \mu \mathrm{g} / \mathrm{ml}$ \\
\hline
\end{tabular}

Tabla 1. Características de los anti-TNF. 
los anti-TNF de 32/1000 pacientes/año: 65/1000, 24/1000 y 13/1000 pacientes/año para Infliximab, Adalimumab y Etanercept, respectivamente El tiempo de aparición varía según la droga, siendo la media de presentación de 3 a 5 meses para Infliximab, 9 a 18 meses para Adalimumab y 12 a 14 meses para Etanercept. ${ }^{115,116}$.

Las manifestaciones clínicas de la tuberculosis suelen ser atípicas, con formas extrapulmonares en el $65 \%$, diseminadas en el $25 \%$. La PPD puede ser negativa por los tratamientos inmunosupresores concomitantes, o por la enfermedad tal como es el caso de la Artritis Reumatoidea. Por todo esto existe retardo en el diagnóstico y tratamiento y mayor morbimortalidad.

Se sugiere suspender el anti-TNF si los pacientes desarrollan tuberculosis mientras reciben el tratamiento antifímico y reanudarlo luego de dos meses de iniciado el tratamiento. ${ }^{15,16,17,18,19,20,21}$

Recientemente se ha descripto reacción paradojal, producto del síndrome de reconstitución inmune al suspender (SRI) el anti-TNF. ${ }^{22}$ Este fenómeno está descripto sobre todo para las formas diseminadas, por tanto hay que ser cauteloso en el momento de la suspensión.

Micobacterias atípicas: La FDA ha reportado 105 casos de infecciones por micobacterias atípicas con $50 \%$ de formas extrapulmonares. La media de aparición fue de 18 semanas con Adalimumab, 35 semanas con Etanercept y 43 semanas con Infliximab. ${ }^{23,24}$

Listeria spp: La FDA ha reportado 92 casos de listeria en pacientes tratados con Infliximab. La meningitis fue la manifestación más frecuente $(75 \%)$ y con una mortalidad del 17,4\%. Posteriormente se han reportado otros 33 casos. La mayoría de los pacientes recibían otros inmunosupresores concomitantemente (corticoides, azatioprina o 6 mercaptopurina). ${ }^{25,26,27,28,29,30}$

Otras bacterias: Gram (+) y Gram (-): Nocardia spp, Legionella spp, Salmonella spp, Bartonella spp, Brucella spp.

- Infecciones respiratorias bajas: La neumonía es frecuente en pacientes con enfermedades autoimunes. El uso de anti-TNF $\alpha$ les agrega un riesgo adicional. Se han descripto casos de sepsis neumocócica severa y neumonía por Legionella spp. ${ }^{31,32,33,34,35}$

- Infección de piel y partes blandas (IPPB): Se ha documentado un aumento en la frecuencia de IPPB en pacientes bajo tratamiento anti-TNF. Hay casos reportados de IPPB severas por nocardiosis cutánea, fascitis necrotizante por S. pneumoniae y $S$. pyogenes (SBGA) e infecciones y sepsis por $S$. aureus. ${ }^{36,37}$

- Infecciones osteoarticulares: Se han descripto casos de artritis séptica por Staphylococcus aureus y gérmenes inusuales (Listeria spp, Salmonella spp, Roseomona mucosa), en estos casos se aconseja discontinuar la droga. ${ }^{3,5,38}$

Se ha reportado que los anti-TNF $\alpha$ podrían incrementar el riesgo de sepsis asociado a las infecciones bacterianas.

\section{- Infecciones micóticas}

Se han documentado infecciones fúngicas invasivas (IFI) en asociación al uso de anti-TNF. Las IFI más frecuentes fueron histoplasmosis, aspergillosis y candidiasis. La mayoría se presentó como neumonía. Según un reporte, el $80 \%$ de los pacientes recibían Infliximab con una media de aparición a los 55 días postratamiento y el $98 \%$ recibía otro agente inmunosupresor. La mortalidad asociada fue del $32 \% .39,40$

Se han publicado 84 casos de neumonía por Pneumocystis jirovecii (PJP) asociado a Infliximab con una media de aparición a los 21 días postratamiento con una mortalidad de $27 \% .^{41}$ Recientemente, un trabajo japonés que incluyó 5000 pacientes con Infliximab documentó 0,4\% de incidencia de PJP.42

\section{- Infecciones virales}

Influenza: No existen datos sobre la incidencia de influenza en pacientes bajo tratamiento con anti-TNF.

Se ha reportado neumonía grave por $\mathrm{H} 1 \mathrm{~N} 1{ }^{43}$

Virus varicela zoster (VZV): Se han documentado 11,1 casos de VZV cada 1000 pacientes año tratados con Infliximab y Adalimumab, 8,9/1000 pacientes año con Etanercept versus 5,6/1000 pacientes año bajo tratamiento convencional en enfermedades autoinmunes. ${ }^{44}$

Es la segunda infección documentada en el registro español de anti-TNF y enfermedades reumatológicas después de la tuberculosis.

Virus herpes simple (VHS): Se ha reportado casos de encefalitis herpética en pacientes bajo tratamiento con Infliximab y Adalimumab. ${ }^{45}$

Podría existir reactivación de VHS en pacientes con antecedentes de herpes recurrente. 
Citomegalovirus (CMV): El rol del CMV en los pacientes bajo tratamiento con anti-TNF con diagnóstico de enfermedad inflamatoria intestinal es discutido. Algunos reportes muestran asociación entre la reactivación de la infección por CMV con exacerbaciones de la enfermedad inflamatoria intestinal resistente a esteroides. ${ }^{46,47,48,49}$

Papilomavirus humano (HPV): Existen algunos estudios que mostraron alta prevalencia de PAP anormales por HPV-18-16 en pacientes con enfermedades autoinmunes como lupus eritematoso sistémico y enfermedad inflamatoria intestinal. ${ }^{50,51}$

Virus hepatitis $\mathrm{C}(\mathrm{HCV})$ : Si bien no existen estudios controlados, una revisión sistemática para evaluar la seguridad de anti-TNF en pacientes con infección crónica por HCV publicada recientemente muestra que su uso es seguro. ${ }^{52}$

Virus hepatitis $B(H B V)$ : El TNF es importante en el control de la infección por HBV. Su bloqueo aumenta la replicación. En los pacientes $\mathrm{HBs} \mathrm{Ag}+$, la reactivación es del $37 \%$ mientras que es del $5 \%$ en pacientes con solo HBcAct. Se observó mayor reactivación con Infliximab que con Etanercept ${ }^{53}$. Dada la complejidad del manejo de los pacientes con coexistencia de infección activa o pasada con HBV, deberían ser monitoreados en un centro con disponibilidad de los tests diagnósticos apropiados.

Virus de la inmunodeficiencia bumana (HIV): El TNFa estaría involucrado en la patogénesis de la infección por HIV, contribuyendo a su propagación. Su bloqueo por lo tanto no produciría mayor deterioro inmunológico. ${ }^{2,3,4,5}$. $\mathrm{La}$ experiencia de tratamiento con anti-TNF en HIV+ es limitada. Se ha utilizado exitosamente en artritis psoriásica y enfermedad inflamatoria intestinal. ${ }^{54,55,56}$

\section{- Infecciones parasitarias}

- S. stercoralis: podría existir riesgo de síndrome de hiperinfección.

- Trypanosoma cruzi (Chagas): no se conocen reportes de la reactivación de esta infección. En lugares donde el Chagas es endémico se sugieren medidas de vigilancia, por el potencial riesgo de reactivación.

\section{ANTI-CITOQUINAS}

No hay reportes de infecciones severas con Anakinra, pero se ha reportado aumento de infecciones cuando se asocia al uso de corticoides de 2,5 veces. ${ }^{60,109,110}$

Se ha reportado una incidencia de infecciones severas, sobre todo de piel y partes blandas de 4,6/100 pacientes años tratados con Tocilizumab. ${ }^{61}$

\section{BLOQUEADORES DE LA SEÑAL COESTIMULADA}

Algunos estudios controlados randomizados en pacientes con artritis reumatoidea han mostrado mayor riesgo de infección en los tratados con Abatacept, particularmente aquellos que recibían otros tratamientos inmunosupresores concomitantes. ${ }^{57,58,59}$ Sin embargo, un reciente metaanálisis mostró que el riesgo de infecciones en pacientes con artritis reumatoidea con el uso de Abatacept comparado con aquellos que recibían tratamiento convencional era igual en pacientes con artritis reumatoidea. ${ }^{59}$ Por otro lado, en pacientes con enfermedad pulmonar obstructiva crónica, se ha reportado un incremento de las infecciones respiratorias. ${ }^{109,111}$

La experiencia clínica con Belatacept es limitada.

No se documentó más riesgo de infecciones serias en pacientes tratados por psoriasis con Alefacept.

\section{JAK-STAT109}

Con estas nuevas moléculas, la experiencia es limitada; se necesita mayor tiempo de seguimiento.

Se ha reportado mayor incidencia de infecciones por Mycobacterias.

Ruxolitinib se ha asociado a una mayor incidencia de infecciones por varicela zoster (estaría indicada la vacunación, previo al inicio de la inmunosupresión), Tofacitinib presenta leve aumento de leucoencefalopatía multifocal progresiva.

\section{BLOQUEANTES DE LAS MOLÉCULAS DE ADHESIÓN} (INTERFIEREN CON LA MIGRACIÓN DE LINFOCITOS T)

El Natalizumab es un anticuerpo monoclonal humanizado IgG4 que se une a la subunidad $\alpha 4 \beta 1$ y $\alpha 4 \beta 7$ de la superficie de los linfocitos $\mathrm{T}$ activados, inhibiendo la unión a las células de adhesión en el sistema nervioso central y el tracto gastrointestinal y bloqueando la migración de linfocitos $\mathrm{T}$ en estos tejidos.

Su uso se asocia con profunda disminución de los linfocitos CD4, CD8 y CD19 en el líquido cefalorraquídeo. 
Se lo utiliza para el tratamiento de Esclerosis Múltiple.

Se han reportado 193 casos de leucoencefalopatía multifocal progresiva (LMP) hasta el 2011, con una incidencia de 2,2 casos $/ 1000$ pacientes durante los primeros 24 meses y 3,7 casos/1000 pacientes con más de 24 meses desde el inicio de la administración de Natalizumab con una mortalidad documentada del $20 \%$.

Los factores de riesgo para desarrollar LMP son el tratamiento inmunosupresor previo, tiempo de exposición a Natalizumab y la presencia de anticuerpos anti-JCV.

Se recomienda un alto índice de sospecha clínica. El diagnóstico se confirma con una PCR para JCV positiva en líquido cefalorraquídeo y la presencia de imágenes sugestivas en la resonancia magnética nuclear.

El tratamiento de LMP asociada a Natalizumab incluye plasmaféresis para su eliminación y acortar el período en el cual el mismo está activo (usualmente varios meses). Se ha descripto exacerbación de los síntomas en los días o semanas posteriores a la realización de la plasmaféresis sugestivo de síndrome de reconstitución inmune. ${ }^{62,63}$

\section{BLOQUEODELAPROLIFERACIÓNDELOSLINFOCITOS TACTIVADOS}

El Basiliximab es un anticuerpo monoclonal que bloquea al receptor CD25 de la IL-2 del linfocito T impidiendo su activación. El mismo parece no asociarse a mayor riesgo de infecciones en trasplante de órgano sólido. ${ }^{64,65,66}$ Los datos de tratamiento de enfermedad injerto contra huésped aguda (EICHA) refractaria a esteroides en trasplante de células progenitoras hematopoyéticas son limitados.

No se ha asociado a mayor riesgo de infecciones en pacientes trasplantados de órganos sólidos con el uso de Daclizumab. ${ }^{67}$ En pacientes con trasplante de células progenitoras hematopoyéticas con EICHA refractaria a esteroides, se documentó mayor frecuencia de infecciones, aunque es discutido el rol del Daclizumab como causante único de las mismas dado el riesgo elevado de infecciones por otras causas en este grupo de pacientes. ${ }^{68,69,70}$

\section{NEUTROPENIZANTE}

En pacientes con leucemia mieloide aguda, el uso de Gemtuzumab se asocia con neutropenia prolongada de hasta aproximadamente 40 días, por lo que tienen mayor riesgo de bacteriemia y neumonía. A pesar de la neutropenia pro- longada no se ha documentado mayor riesgo de infecciones fúngicas invasivas asociadas al uso de Gemtuzumab. ${ }^{71}$

\section{DEPLECIONADORES DE LINFOCITOS B}

El Rituximab es un anticuerpo monoclonal IgG1quimérico que se une a CD20 de los linfocitos B normales y malignos, produciendo depleción de los linfocitos $\mathrm{B}$ a los pocos días de iniciado el tratamiento; la misma persiste por 6 a 9 meses despues de suspendido.

En general, los niveles de inmunoglobulina permanecen estables o discretamente disminuidos en pacientes con enfermedades autoinmunes; sin embargo en pacientes con Linfomas, algunos autores han documentado disminución de inmunoglobulinas. Por lo cual estos niveles deben ser vigilados y reemplazados.

No afecta CD3, CD4,CD8 o células T natural killer por lo que producirá mínimo efecto sobre la inmunidad celular.

Se lo utiliza en el tratamiento del Linfoma y enfermedades autoinmunes como artritis reumatoidea, crioglobulinemia mixta, pénfigo, vasculitis, esclerosis múltiple y púrpura trombocitopénica idiopática. ${ }^{82,83,84,85}$

En diferentes trabajos randomizados en pacientes con enfermedad oncohematológica, cuando se comparó el esquema clásico CHOP (Ciclofosfamida + Doxorubicina + Vincristina + Corticoides) versus R-CHOP (el esquema previo más el agregado de Rituximab) no hubo diferencia en la incidencia de infecciones. ${ }^{80,81}$ Sin embargo, en dos metaanálisis, la terapia de mantenimiento con Rituximab en Linfomas se asoció con mayor riesgo de infecciones, todos estos pacientes recibían además corticoides, con lo cual el rol del Rituximab sería discutible. ${ }^{82,83}$

En Reumatología, cuando se comparó el esquema Metotrexato + anti-TNFa con o sin Rituximab no hubo diferencias estadísticamente significativas en el número de infecciones. ${ }^{84}$

\section{- Infecciones virales}

No se ha reportado aumento de reportes de infecciones en pacientes VIH positivos, ni en infectados con hepatitis C. Tampoco se han reportado reactivaciones de las infecciones causadas por virus del grupo herpes.

Por tanto nos referiremos a la hepatitis B y a la leucoencefalopatía multifocal progresiva.

Reactivación de virus de la hepatitis $B(H B V)$ : Se han descripto pérdida de anticuerpos protectores anti-HBsAgy 
reactivación fulminante de $\mathrm{HBV}$ en pacientes en tratamiento con Rituximab, particularmente en aquellos con HBV crónica antes de iniciado el tratamiento. La reactivación según las diferentes series en la HBV crónica (HBsAg+) llega al $42 \%$ y a $1,5 \%$ en pacientes con anti-HBsAg+. En el caso de los pacientes con hepatitis pasada (HBsAg negativo, core+ $\mathrm{y}$ antiHBsAg+), la reactivación puede llegar hasta el $25 \%$. Las reactivaciones presentan una mortalidad cercana al $52 \%$.

Si bien la reactivación ocurre más frecuentemente dentro de los 6 meses de iniciada la droga, hay reportes de casos hasta los 24 meses luego de finalizada la misma. Por tanto es estrictamente necesario conocer el estado serológico del paciente antes de iniciar el tratamiento con Rituximab, ya que en caso de ser negativo se recomendará la vacuna y si tiene marcadores positivos deberá vigilarse y/o indicarse antivirales según corresponda. ${ }^{87,88}$

Leucoencefalopatía Multifocal Progresiva: Se han reportado casos de LMP asociada al uso de Rituximab, la mayoría en pacientes que presentaban enfermedades oncohematológicas. Muchos de estos pacientes habían recibido previamente o concomitantemente otras drogas inmunosupresoras. La infección se manifestó con una media de 6 dosis de Rituximab y con un tiempo medio de exposición a la droga de 16 meses. La mortalidad descripta fue del $90 \% .{ }^{89}$

\section{- Infecciones bacterianas}

No hay reporte de aumento de incidencia de TB, igualmente está recomendada la realización de PPD para evitar la reactivación de la misma.

\section{- Infecciones micóticas}

Algunos trabajos mostraron mayor incidencia de infección por $P$. jirovecii en pacientes con linfoma tratados R-CHOP comparado a CHOP. Muchos de estos pacientes recibían corticoides $\mathrm{u}$ otros inmunosupresores, por lo tanto el rol del Rituximab como agente predisponente a estas infecciones es discutido. ${ }^{90}$

\section{- Infecciones parasitarias}

- S. stercoralis: podría existir riesgo de síndrome de hiperinfección.

- Trypanosoma cruzi (Chagas): no se conocen reportes. En lugares donde el Chagas es endémico se sugiere medidas de vigilancia, por el potencial riesgo de reactivación.

\section{DEPLECIONADORES DE LINFOCITOS B Y T}

El Alentuzumab es un anticuerpo monoclonal humanizado IgG 1 que se une al CD52 de los linfocitos B y T, monocitos, macrófagos y células natural killer produciendo la lisis de estas células.

Se lo utiliza para el tratamiento de leucemia linfática crónica, enfermedad linfoproliferativa y trasplantes.

Produce un deterioro de la inmunidad celular y humoral sostenido.

Entre las 2 a 4 semanas de administrado se documenta una linfopenia profunda con disminución de CD4 y CD8, que comienzan a recuperarse después de los 6 meses de suspendido el tratamiento.

La incidencia de infecciones oportunistas es muy elevada, siendo aproximadamente de 56 al 59\%, comparado con un $29 \%$ en el mismo grupo de pacientes sin Alentuzumab llega a $29 \%$. Los pacientes con Leucemia linfática crónica tienen un riesgo mayor si estos recibieron previamente análogos de purinas o más de 3 ciclos de quimioterapia.

Dada la potente inmunosupresión que produce está contraindicado el uso concomitante con terapia radiante corporal total.

\section{- Infecciones virales ${ }^{72,73,74,75,76,77,78,79}$}

Dada la alta incidencia de reactivación de CMV, está recomendada la vigilancia en los pacientes seropositivos con carga viral en forma semanal a bisemanal hasta los 6 meses de finalizado el tratamiento, la profilaxis universal no está recomendada.

Las reactivaciones y formas graves por herpes simplex y zoster son muy frecuentes, por ello está indicada la profilaxis hasta 2 meses de finalizado el Alentuzumab.

\section{- Infecciones micóticas ${ }^{72,73,74,75,76,77,78,79}$}

Debido a la elevada incidencia de infecciones micóticas en este grupo de pacientes, si bien no se encuentra formalmente indicada, está recomendado el monitoreo con galactomananos; este panel cree conveniente indicar profilaxis para hongos filamentosos de acuerdo a la incidencia de infección de cada centro.

\section{- Infecciones bacterianas}

Previo al inicio del tratamiento debe realizarse PPD; en caso de ser positiva se recomienda descartar infección activa. Se indicará tratamiento de la infección latente durante 9 meses. Se ha reportado aumento de infecciones (meningitis) por Listeria spp. 


\section{- Infecciones parasitarias}

- S. stercoralis: podría existir riesgo de síndrome de hiperinfección.

- Trypanosoma cruzi (Chagas): no se conocen reportes. En lugares donde el Chagas es endémico se sugiere medidas de vigilancia, por el potencial riesgo de reactivación.

\section{MEDIDAS DE PREVENCIÓN SEGÚN EL BIOLÓGICO}

\section{- Evaluación inicial}

1. Historia clínica completa, donde se deberá tener en cuenta: - Lugar de residencia, viajes recientes.

- Antecedentes de contacto efectivo con casos de tuberculosis.

- Inmunizaciones previas.

- Antecedentes de infección por virus de herpes simple $\mathrm{y}$ varicela zoster, hepatitis $\mathrm{u}$ otras infecciones.

2. Examen clínico anual:

- Identificar focos de infección.

- Evaluación estado dental.

- Visita ginecológica/PAP.

- Radiografía tórax.

- PPD o QuantiFERON-TBC. Esta última no está aún disponible en nuestro país.

3. Laboratorio:

- Hemograma/Hepatograma.

- Recuento de linfocitos totales y CD4 (para suspensión de profilaxis).

- Serologías:

- HIV IgG (ELISA).

- VDRL. Se debe tratar en caso de ser positivo.

- Enfermedad de Chagas (IFI, ELISA, IHA). Para considerar positiva, se debe tener al menos dos testeos positivos (vigilar con PCR y Strout).

- Toxoplasmosis IgG. Recomendar evitar comer carnes y/o vegetales crudos, así como limpiar la excreta de gatos y las tareas de jardinería.

- VZV IgG.

- Sarampión IgG.

- HBV (HBsAg-core, Anti-HBsAg, HBsAc).

- HCV IgG.

- HAV IgG.

\section{Dieta}

- Se desaconseja el uso de productos lácteos no pasteurizados, así como el consumo de quesos blandos tipo brie, roquefort, camambert, dado que no tienen un proceso que garantice la ausencia de alta carga bacteriana.

- Lavar adecuadamente las frutas y verduras que van a ser ingeridas crudas.

- Ingerir alimentos seguros (carne, pescado y huevos bien cocidos).

\section{Ambientales}

- Evitar trabajos de jardinería, cuidado de pájaros o en las proximidades de áreas de construcción. Si no se pueden evitar, deberá usarse barbijo cuando realice estas actividades.

- Uso de preservativo.

- Consulta pre-viaje.

\section{- Anti-TNF $\alpha^{2,3,4,5,12,13,88,92,93,94,95}$}

1. Tuberculosis

PPD: Se considera positiva a una reacción igual o mayor a $5 \mathrm{~mm}$ en el huésped inmunocomprometido y mayor a $10 \mathrm{~mm}$ en el inmunocompetente. La negatividad de esta prueba no descarta la tuberculosis latente, ya que muchos pacientes están bajo tratamiento inmunosupresor como corticoides, metotrexate; o padecen una enfermedad que per se da anergia como es el caso de la AR.

Cuando contemos con técnicas de IGRA (ensayo de liberación de interferón gamma) basadas en la liberación de TNF $\gamma$ luego de la exposición al antígeno de tuberculosis (QuantiFERON Gold in tube QTF-GIT y T-SPOT.TB), dado que no producen reacción cruzada con el bacilo de Calmette-Guérin presente en la BCG, será util para descartar falsos positivos por BCG previa y desenmascarar los casos de anergia, además de aportar el resultado en el mismo día, sin tener que recitar al paciente en 48 hs. (Figura 1)

El Centro de Control de Enfermedades de Estados Unidos (CDC) sugiere no administrar terapia con anti-TNFa hasta completar el tratamiento de tuberculosis latente o activa. En la práctica, no se puede demorar el inicio del tratamiento ya que la indicación del anti-TNF puede ser urgente según las condiciones del paciente, por lo que la Guías Europeas acortan este tiempo sugiriendo tratar 2 semanas la TB latente antes de comenzar el anti-TNFa. 


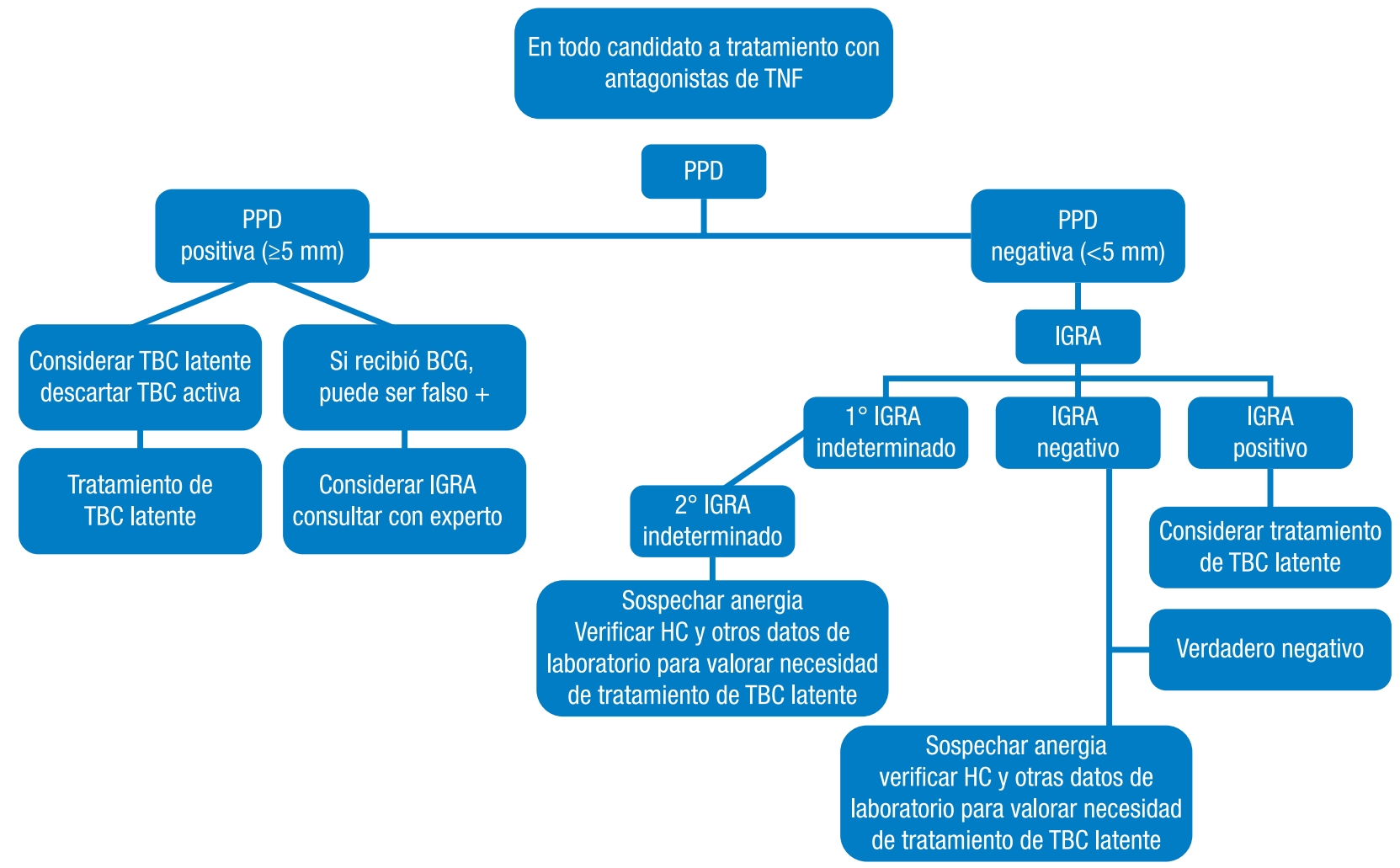

Figura 1. Algoritmo PPD/IGRA. Adaptado de la J of Rheumatology 2011(7),1234.

Se deberá repetir la PPD cada doce meses en los pacientes PPD negativa inicial.

En caso de anergia, se puede realizar una segunda PPD a las 2 semanas como efecto booster para generar hipersensibilidad. Por el momento, en Argentina, ante la falta de métodos IGRA se aceptan ambas opciones, la realización de PPD en uno o dos tiempos.

El esquema de tratamiento de la tuberculosis latente consiste en isoniazida por el término de nueve meses. Este esquema deberá ser prolongado a doce meses en caso de inmunosupresión severa.

\section{Virus herpes simple}

En pacientes con antecedentes de herpes simple recurrente, se puede considerar la profilaxis mientras dure la inmunosupresión con los siguientes antivirales:

- Aciclovir $400 \mathrm{mg}$ cada 12 horas.

- Valaciclovir 500 mg/día.

- Fanciclovir 250 mg 2 cada 12 horas.

\section{Virus varicela zoster}

Se sugiere dosaje de anticuerpos IgG para evaluar necesidad de vacunación previa a la inmunosupresión, debido a que esta vacuna está contraindicada en los pacientes inmunocomprometidos.

\section{Virus del papiloma humano (HPV)}

Como fue anteriormente señalado, se deberá realizar examen ginecológico basal y controles posteriores anuales para evaluar aparición de HPV. La infección pasada o presente no es una contraindicación para iniciar el tratamiento inmunosupresor.

\section{Virus de hepatis $\mathrm{C}$ (VHC)}

Durante el tratamiento, se debe realizar seguimiento con Carga Viral RNA del virus de hepatitis C.

\section{Virus de hepatitis B (VHB)}

En base a las serologías realizadas antes del incio del tratamiento inmunosupresor, se realizará el siguiente seguimiento: 
- En pacientes con HBsAg positivo, se deberá solicitar carga viral.

- Si el paciente tiene HBsAg positivo con enfermedad activa se indica tratamiento y control de la enfermedad antes de iniciar anti-TNF.

- Si el paciente tiene HBsAg positivo y se encuentra asintomático, se deberá indicar profilaxis antiviral entre dos a cuatro semanas previas a anti-TNF y continuar por seis meses luego de discontinuarla.

- Si el paciente tiene $\mathrm{HBcAc}$ positivo con $\mathrm{HBs} \mathrm{Ag}$ y antiHBsAc negativos, no está recomendada la profilaxis de rutina. Se deberá realizar monitoreo con enzimas hepáticas y carga viral cada uno a tres meses.

Antivirales recomendados:

- Lamivudina: Puede ser indicada en pacientes con inmunosupresión menor a seis meses. No se sabe si es efectiva después de este tiempo.

-Entecavir o adefovir: Pueden ser indicados en pacientes con inmunosupresión mayor a seis meses.

\section{Micosis}

- Criptococosis: No hay recomendaciones escritas con respecto a screening o profilaxis en esta situación clínica. En aquellos pacientes con antecedentes de infección por Cryptococcus spp. se sugiere indicar profilaxis antifúngica secundaria durante el tratamiento con anti-TNF $\alpha$ con Fluconazol.

- Pneumocystis jirovecii, se sugiere indicar profilaxis en:

a) Pacientes con al menos dos inmunosupresores que incluyan el uso de corticoides.

b) Pacientes con linfopenia ( $<600 / \mathrm{ml}$ linfocitos) y CD4 $<300 / \mathrm{ml}$.

- Droga elección:

TMS 160/800 mg 3 veces por semana.

TMS 80/400 mg todos los días.

- Alternativa:

Dapsona $100 \mathrm{mg} / \mathrm{d}$.

Dapsona $200 \mathrm{mg}+$ Pirimetamina $75 \mathrm{mg}+$ Leucovorina (esta última para evitar la toxicidad medular de este esquema) una vez a la semana.

Pentamidina inhalada $300 \mathrm{mg} 1$ vez por mes (es necesario un nebulizador especial como el Respigard III o similar). No evita las formas sistémicas de la enfermedad.

\section{Parasitosis}

- S. stercoralis: Se sugiere screening previo al inicio del tratamiento en todo paciente que va a ser sometido a inmunosupresión en nuestro país, ya que no sólo el noreste argentino es área endémica sino que las zonas de riesgo se han extendido. Se deberá realizar testeo a través de:

- Coproparasitológico seriado: realizar al menos tres muestras.

- Evaluar parasitológico en sondeo duodenal en pacientes con eosinofilia y coproparasitológico seriado negativo.

- La serología ELISA no está disponible en nuestro pais.

En caso de screening positivo se indica tratamiento con:

- Elección:

Ivermectina $200 \mu \mathrm{g}$ una vez por día, por 1 a 2 días.

- Alternativas:

Tiabendazol $25 \mathrm{mg} / \mathrm{kg}$ (máximo 1,5 g) dos veces al día (luego de las comidas) por tres días.

Albendazol 400mg dos veces al día, durante tres días.

Mebendazol $100 \mathrm{mg}$ cada 12 horas, por tres semanas.

Debido al riesgo de infección diseminada, está indicado un control parasitológico (copro o sondeo dudodenal) negativo antes del inicio de la inmunosupresión.

- Enfermedad de Chagas: Se sugiere testeo en todos aquellos que viven en Argentina o provenientes de otros países con Chagas endémico:

- Serología (IFI-ELISA-HAI)

- En caso de que dos o más reacciones sean positivas se sugiere monitoreo.

Monitoreo:

Se debe realizar Strout semanal o PCR, este último es el método recomendado, dado que antecede en más de 1 mes a la parasitemia, durante el período de máxima imunosupresión y monitoreo mensual hasta la finalización de la inmunosupresión.

Tratamiento:

En caso de PCR y/o parasitemia positiva, debe instaurarse tratamiento por 30 días con benznidazol 5 a $7 \mathrm{mg} / \mathrm{k} / \mathrm{d}$ por treinta días, una alternativa es el benznidazol 8 a $10 \mathrm{mg} / \mathrm{k} / \mathrm{d}$.

\footnotetext{
9. Recomendaciones en pacientes que serán sometidos a cirugía

Según algunos trabajos, el riesgo de infección del sitio quirúrgico no se incrementa en pacientes con artritis reumatoidea tratados con anti-TNF $\alpha$ previo a la cirugía.
} 
Algunos trabajos mostraron que continuar con antiTNF $\alpha$ en el postoperatorio se asoció con mayor dehiscencia y sangrado de la herida comparado con los que suspendieron el anti-TNFa.

Se sugiere:

- Discontinuar anti-TNF antes de realizar una cirugía. El tiempo de discontinuación es diferente para cada antiTNF según su vida media.

- Se puede reanudar el anti-TNF $\alpha$ dos semanas después de la cirugía o de completar la cicatrización de la herida en ausencia de infección.

\section{- Alentuzumab}

\section{Pneumocysitis jirovecci}

Desde el inicio del tratamiento hasta 9 a 12 meses de finalizado el tratamiento y si es posible con CD4 $>200 / \mathrm{mm}^{3}$.

Droga de elección:

- TMP/SMX (160/800) 1 comprimido por día lunes, miércoles y viernes.

Drogas alternativas:

- Dapsona $100 \mathrm{mg} / \mathrm{d}$.

- Dapsona 200 mg + Pirimetamina 75 mg + Leucovorina (esta última para evitar la toxicidad medular de este esquema) una vez a la semana.

- Pentamidina inhalada $300 \mathrm{mg} 1$ vez por mes (es necesario un nebulizador especial Respigard III o similar), no evita las formas sistémicas de la enfermedad ya que solo ingresa al pulmón.

\section{Virus herpes simple y varicela zoster}

Desde el inicio del tratamiento hasta 2 meses de finalizado el mismo.

Elección:

- Aciclovir 400 mg cada 12 horas.

- Valaciclovir 500 mg al día.

\section{Tuberculosis}

Seguir el mismo algorritmo que con anti-TNF $\alpha$.

\section{Strongiloides y Chagas}

Seguir el mismo algorritmo que con anti-TNFa.

Vigilancias indicadas:

- Citomegalovirus: Se realizará vigilancia de la rectivación de citomegalovirus, no estando indicada la profilaxis universal, mediante carga viral por PCR en tiempo real o Ag pp65 en forma semanal. La vigilancia se deberá extender hasta los seis meses de finalizada la terapia.

- Infecciones fúngicas invasivas: Se realizará monitoreo bisemanal con el antígeno de galactomanano y/o $\beta-\mathrm{D}$ glucano.

\section{- Rituximab}

Por el riesgo de reactivación del virus de Hepatitis B y la elevada morbimortalidad se sugiere solicitar la determinación de $\mathrm{HBsAg}, \mathrm{HBcAc}$ y HBsAc antes de iniciar un tratamiento con Rituximab. Según estos resultados, se optará por:

- HBsAg (-), HBcAc (-) y HBsAc (-): paciente naive, se sugiere vacunación con un esquema rápido de tres dosis (030-60 días) con revacunación al año, si es que se va a iniciar rápidamente esta droga; sino esquema convencional $(0,1 \mathrm{y}$ 6 meses).

- HBsAg (+): se desaconseja el uso de Rituximab. Si por la enfermedad del paciente no existiera otra opción terapéutica, debe realizarse profilaxis antiviral junto al seguimiento estricto de la carga viral y en caso de aumento de $>1 \lg _{10}$ o $>2000 \mathrm{IU} / \mathrm{ml}$ deberá suspenderse la droga.

- HBsAg (-), HBcAc (+) y HBsAc ( 210$)$ : indica una infección pasada, pero puede reactivarse en caso de inmunocompromiso por pérdida del control linfocitario.

En este caso hay dos conductas:

1) Seguimiento con carga viral mensual y HBsAc cada 2 semanas, tratando de mantener niveles $\geq 100$. Si la determinación de carga viral es $>2000 \mathrm{IU} / \mathrm{ml}$, iniciar profilaxis así como ante la pérdida del título de anticuerpos.

2) Dar profilaxis a todos los pacientes, si no contamos con la posibilidad de realizar carga viral mensual y anticuerpos cada 2 semanas.

- HBsAg (-), $\mathrm{HBcAc}(+)$ y HBsAc (-): puede responder a dos causas; puede ser un falso positivo o que se trate de una HBV oculta.

Se sugiere indicar una dosis de vacuna para HBV. Si presenta respuesta a la misma con detección de anticuerpos anti-HBsAg a los 30 a 40 días, es un falso positivo y debemos vacunarlo como si fuera naive. En caso de no obtener respuesta, se trata core+, como expresión de infección HBV oculta, por una mutante que impide hacer $\mathrm{HBsAc}$, en este caso se deberá pedir carga viral e instaurar profilaxis. 
- HBsAc (+) Core y HBsAg (-): puede corresponder a un paciente que ha sido vacunado o a un porcentaje de pacientes que no han sido vacunados y se trata de $\mathrm{HBV}$ oculta; para ello debemos pedir DNA HBV e instaura profilaxis en caso de ser positiva.

Se desaconseja el seguimiento con enzimas, dado que la carga viral antecede al aumento de enzimas en aproximadamente 8 semanas y es la carga viral la que determina el flair (reactivación). Una vez instaurada la hepatitis, la mortalidad es mayor al 50\%. (Tabla 2)

\begin{tabular}{|c|c|c|c|c|c|}
\hline HBsAg & HBsAC & HBcAc & Status & Conducta & Antiviral \\
\hline- & - & - & Naive & Vacunar & No \\
\hline+ & - & - & $\begin{array}{c}\text { Replicación } \\
\text { activa }\end{array}$ & $\begin{array}{c}\text { DNA basal y } \\
\text { seguir con CV }\end{array}$ & Sí \\
\hline- & + & + & Pasada & $\begin{array}{c}\text { Monitoreo } \\
\text { HBsAc y CV }\end{array}$ & $\begin{array}{c}\text { Sí o Controlar } \\
\text { con HBsAc }\end{array}$ \\
\hline- & - & + & $\begin{array}{c}\text { Infección oculta } \\
\text { versus Falso + }\end{array}$ & $\begin{array}{c}\text { Vacunar, si hace } \\
\text { HBsAc vacunar, } \\
\text { de lo contrario } \\
\text { pedir DNA basal }\end{array}$ & $\begin{array}{c}\text { Profilaxis versus } \\
\text { seguimiento }\end{array}$ \\
\hline- & + & - & $\begin{array}{c}\text { Vacunado } \\
\text { versus Infección } \\
\text { oculta }\end{array}$ & DNA+ & Sí \\
\hline
\end{tabular}

Tabla 2. Algoritmo de conductas según serología de hepatitis $B$.

Antivirales recomendados:

- Entecavir o adefovir: son de elección cuando la inmunosupresión es mayor a seis meses, como es el caso del Rituximab.

Duración: hasta 2 años posterior a la finalización del tratamiento con Rituximab.

\section{VACUNAS $96,97,98,99,100,101,102,103,104,105,106,107,108,112,113,114$}

La inmunización es el pilar esencial para prevenir infecciones y no hay reactivación de las enfermedades inflamatorias posterior a la vacunación.

Las vacunas activas (agentes infecciosos vivos) están contraindicadas en inmunocomprometidos, para ello es esencial definir inmunocompromiso.

\section{Inmunocompromiso:}

- Metilprednisona (o su equivalente) a dosis $>20 \mathrm{mg} / \mathrm{d}$ por más de 2 semanas.

- Metotrexate $>0,4 \mathrm{mg} / \mathrm{kg} / \mathrm{semana}$.

- Azatioprina $>3 \mathrm{mg} / \mathrm{kg} / \mathrm{d}$.

- 6-Mercaptopurina $<1,5 \mathrm{mg} / \mathrm{k} / \mathrm{d}$.

- Agentes biológicos (anti-TNF, Rituximab, etc.).
- Quimioterapia.

- Inmunodeficiencias combinadas primarias.

- Menos de $200 \mathrm{CD} 4 / \mathrm{mm}^{3}$.

- Trasplante.

\section{Tipos de vacunas}

- Inactivadas: no contienen agentes infecciosos vivos.

- Activas: contienen agentes infecciosos vivos atenuados.

\section{¿Cuándo vacunar?}

El momento ideal para prescribir la vacunación es al momento del diagnóstico de la enfermedad de base y antes de que reciban el tratamiento inmunosupresor.

Las vacunas activas están contraindicadas en pacientes inmunocomprometidos por el riesgo de provocar la enfermedad, veremos más adelante en qué condiciones pueden administrarse.

En el caso de las vacunas inactivadas, si bien no hay riesgo de vacunar durante el tratamiento inmunosupresor, la respuesta suele ser menor.

Se recomienda vacunar a los pacientes al menos 2 semanas antes de iniciar el tratamiento inmunosupresor. Si no se pudo vacunar antes de iniciarlo, se deberá vacunar igual aunque la respuesta podría ser menor en los pacientes bajo anti-TNFa.

En el caso de pacientes bajo tratamiento con Rituximab, se recomienda vacunar a las seis a ocho semanas de iniciado y repetir a los seis a diez meses de la última dosis, dada la mala respuesta a todas las vacunas intratratamiento.

- Se ha reportado menor respuesta con Abatacept a la vacuna antineumocócica y con los anti-TNF para la cepa $\mathrm{B}$ de la vacuna antigripal. La combinación de agentes anti-TNF $\alpha$ y Metotrexato reduce la respuesta de la vacuna antineumocócica y antigripal.

\section{Vacunas indicadas}

\section{Inactivadas:}

1. Antineumocócica Conjugada 13 valente (PCV) y Polisacárida (PPSV): se indicará 1 dosis de PCV y a los 2 meses 1 dosis de PPSV, con un refuerzo a los 5 años de PPSV y otro luego de los 65 años de edad.

2. Antigripal: una dosis anual en el otoño.

3. Hepatitis B: en los pacientes seronegativos, se recomienda el esquema clásico: 0, 1 y 6 meses. Se debe realizar control de anticuerpos a los 30 a 40 días con el fin de determinar la seroconversión ( $\geq 10 \mathrm{UI})$. 
4. Hepatitis A: en los pacientes seronegativos se administrarán dos dosis separadas por 6 meses. 720 UI en menores de 18 años y 1440 UI en mayores de 18 años. No es necesario el control ulterior de anticuerpos.

5. Difteria-Tétanos (DTa): está recomendada una dosis cada diez años. En aquellos pacientes que han recibido la última dosis hace más de diez años, y que han recibido el esquema primario completo ( 3 o 5 dosis), sólo debe administrarse un refuerzo con revacunación cada diez años. Aquellos que no recuerdan haber sido vacunados en su vida (vírgenes de vacunación antitetánica) deberán recibir un esquema completo consistente en tres dosis a 0, 30 y 360 días con refuerzo cada 10 años. Una de estas dosis debe contener Pertusis acelular (DTPa).

6. HPV cuadrivalente: 3 dosis (0, 1 ó 2 y 6 meses) entre los 11 y 26 años.

7. Meningococo cuadrivalente (A,C,Y,W135): indicado en caso de asplenia funcional o anatómica; recordar separar por 1 mes de la antineumocócica conjugada, pues baja la efectividad.

\section{Vacunas activas:}

Aplicar 1 mes antes de que el paciente se encuentre bajo tratamiento inmunosupresor y contraindicadas en inmunocomprometidos, por el riesgo de enfermedad y mortalidad.

1. Varicela: 2 dosis separadas por un mes en mayores de 13 años y una dosis en menores de esa edad. En pacientes seronegativos (susceptibles).

2. Zoster: esta vacuna ha demostrado disminuir la neuralgia post-herpética y la severidad de la enfermedad (aún no está licenciada en nuestro país) y está indicada en mayores de 60 años seropositivos o en aquellos mayores de 50 años que van a recibir terapia inmunosupresora.

3. Sarampión (MMR): indicada en pacientes seronegativos.

\section{Vacunas en convivientes:}

Dado que los pacientes bajo terapia inmunosupresora alcanzan niveles más bajos de anticuerpos o pueden perderlos, debemos vacunar al entorno para protegerlo:

1. Influenza: anualmente en otoño.

2. Triple viral (MMR): en caso de ser susceptible.
3. Vacuna para varicela (VZV): en caso de ser susceptible se administrarán dos dosis separadas por 1 mes. Si el conviviente vacunado desarrolla exantema, se deberá indicar aislamiento de contacto.

4. Vacuna polio inactivada (Salk).

5. Vacuna Rotavirus.

Está contraindicado el uso de vacuna antipoliomielítica oral (Sabin) en los convivientes de huéspedes inmunocomprometidos. Si inadvertidamente algún conviviente recibe esta vacuna, el paciente no podrá estar en contacto con éste durante un mes.

En caso de haber vacunado para Rotavirus a un conviviente (indicada en menores a 1 año) sólo debe cuidarse que el cambio del pañal lo realice otra persona, o en caso de diarrea extremar higiene de manos durante las primeras 2 a 3 semanas; igualmente el contagio es poco frecuente.

\section{Vacunas contraindicadas en caso de inmunocompromiso:}

- BCG

- Sarampión / rubéola / paperas (triple viral)

- Varicela

- Varicela zoster

- Fiebre amarilla

- Influenza inhalatoria

- Salmonella tiphy oral

- Rotavirus

\section{Bibliografía}

1. Hansel TH, Kropshofer H, Singer T, et al. The safety and side effects of monoclonal antibodies. Nature. 2010; 9:325-38.

2. Koo S, Marty FM and Baden LR. Infectious Complications Associated with Immunomodulating Biologic Agents. Hematol Oncol Clin N Am 2011; 25:117-38.

3. Saketkoo LA, Espinoza LR. Impact of Biologic Agents on Infectious Diseases. Infect Dis Clin N Am 2006; 20:931-61.

4. Khanna D, Mc Mahon M and Furst D E. Safety of Tumour Necrosis Factor-alfa Antagonist. Drug Safety 2004; 27:308-21.

5. Garcia JM, Moya L. Complicaciones infecciosas asociadas al uso de fármacos antagonistas del factor de necrosis tumoral: Revisión de conjunto. Enferm Infecc Microbiol Clin 2005; 23:551-9. 
6. Mariette X, Gottenberg J-E, Ravaud P, et al. Registries in rheumatoid arthritis and autoimmune diseases: data from the French registries. Rheumatology 2011; 50:222-29.

7. Lawrance I, Radford-Smith G, Bamton P, et al. Serius infections in patients with inflammatory bowel disease receiving anti-tumor-necrosis-factor-alpha therapy: An Australian and New Zealand experience. Gastroenterol and Hepatol 2010; 25:1732-8.

8. Dommasch ED, Abuabara K, Shin DB. The risk of infection and malignancy with tumor necrosis factor antagonists in adults with psoriastic disease: A systematic rewiew and meta-analysis of randomized control trials. J Am Acad Dermatol 2011; 64:1035-50.

9. Orlando A, Armuzzi A, Papi C, et al. The Italian Society of Gastroenterology and the Italian Group for the study of Inflammatory Bowel Disease Clinical Practice Guidelines: The use of tumor necrosis factor-alpha antagonist therapy in Inflammatory Bowel Disease. Digestive and Liver Disease 2011; 43:1-20.

10. Galloway JB, Hyrich KL, Mercer LK, et al. AntiTNF therapy is associated with an increased risk of serious infections in patients with rheumatoid arthritis especially in the first 6 months of treatment: updated results from the British Society for Rheumatology Biologics Register with special emphasis on risks in the elderly. Reumatology 2011; 50:12431.

11. De la Vega M. Primer reporte de eventos adversos de tratamientos biológicos en la Argentina. Informe de Registro BIOBADASAR. Rev Arg Reumatol 2011; 22:40-54.

12. Garcia-Vidal C, Rodriguez-Fernandez S, Teijon $S$, et al. Risk factor for opportunistic infections in Infliximab treatment patients importance of screening in prevention. Eur J Clin Microbiol Infect Dis 2009; 28:331-3.

13. Fessler BJ. Infectious diseases in systemic lupus erythematosus: risk factors, management and prophylaxis. Best Pract Res Clin Rheumatol. 2002; 16:281-91.

14. Caporali R, Caprioli M, Bobbio-Pallavicini F, Montecucco C. DMARDS and infections in rheumatoid arthritis. Autoimmun Rev. 2008; 8:139-43.

15. Furst DE. The risk of infections with biologic therapies for rheumatoid arthritis. Semin Arthritis Rheum. 2010; 39:327-46.

16. Askling J, Fored CM, Brandt L, et al. Risk and case characteristics of tuberculosis in rheumatoid arthritis associated with tumor necrosis factor antagonists in Sweden. Arthritis Rheum 2005; 52:1986-92.

17. Mladenovic V, Domljan Z, Rozman B, et al. Infection in patients with rheumatoid arthritis and the effect of infliximab therapy. Arthritis Rheum 2004; 50:372-9.

18. Carmona L, Hernández-García C, Vadillo C, et al. Increased risk of tuberculosis in patients with rheumatoid arthritis. J Rheumatol 2003; 30:1436-9.

19. Dixon WG, Hyrich KL, Watson KD, et al. Drug-specific risk of tuberculosis in patients with rheumatoid arthritis treated with anti-TNF therapy: results from the British Society for Rheumatology Biologics Register (BSRBR).Ann Rheum Dis. 2010; 69:522-8.

20. Iseman MD Mycobacterial infections in the era of modern biologic agents. Am J Med Sci. 2011; 341:278-80.

21. Wallis RS, Broder MS, Wong JY, et al. Granulomatous infectious diseases associated with tumor necrosis factor antagonists. Clin Infect Dis. 2004; 38:1261-5.

22. Melboucy-Belkhir S, Flexor G, Stirnemann J, et al. Prolonged paradoxical response to anti-tuberculous treatment after infliximab. Int J Infectious Dis 2010, 14s:333-4.

23. Winthrop KL, ChangE, Yamashita S, et al. Nontuberculous mycobacteria infections and anti-Tumor Necrosis Factor-terapy. Emerg Infect Dis 2009; 2009; 15:1556-61.

24. Besada E. Rapid growing mycobacteria and TNFa blockers: case report of fatal lung infection with Mycobacterium abscessus in a patient treated with infliximab, and literature review. Clin Exp Rheumatol 2011; 29:705-7.

25. Kesteman T, Yombi JC, Gigi J, Durez P. Listeria infections associated with infliximab: case reports. Clin Rheumatol. 2007; 26:2173-5.

26. Slifman NR, Gershon SK, Lee JH, Edwards ET, Braun MM. Listeria monocytogenes infection as a complication of treatment with tumor necrosis factor alpha-neutralizing agents. Arthritis Rheum. 2003; 48:319-24.

27. Peña-Sagredo JL, Hernández MV, FernandezLlanio N, et al. Listeria monocytogenes infection in patients with rheumatic diseases on TNF-alpha antagonist therapy: the Spanish Study Group experience. Clin Exp Rheumatol. 2008; 26:854-9. 
28. Murphy G, Schmidt-Martin D, Hynes BG, et al. Systemic listeriosis with adalimumab therapy. J Clin Rheumatol. 2009; 15:369-70.

29. Ramos JM, García-Sepulcre MF, Masiá M, Brotons A, et al. Listeria monocytogenes infection in patients with inflammatory bowel diseases receiving anti-tumor necrosis factor therapy. Rev Esp Enferm Dig. 2010; 102:614-6.

30. Kelesidis Theodoros, Salhotra Amandeep, Fleisher $\mathrm{J}$, et al. Listeria endocarditis in a patient with psoriatic arthritis on infliximab: Are biologic agents as treatment for inflammatory arthritis increasing the incidence of listeria infections? J Infection 2010; 60:386-96.

31. Tubach F, Ravaud P, Salmon-Céron D, et al. Emergence of Legionella pneumophila pneumonia in patients receiving tumor necrosis factor-alpha antagonists. Clin Infect Dis. 2006; 43:e95-100.

32. Beigel F, Jürgens M, Filik L, et al. Severe Legionella pneumophila pneumonia following infliximab therapy in a patient with Crohn's disease. Inflamm Bowel Dis. 2009; 15:1240-4.

33. Wondergem MJ, Voskuyl AE, van Agtmael MA. A case of legionellosis during treatment with a TNFalpha antagonist. Scand J Infect Dis. 2004; 36:310-1.

34. Li Gobbi F, Benucci M, Del Rosso A. Pneumonitis caused by Legionella pneumoniae in a patient with rheumatoid arthritis treated with anti-TNFalpha therapy (infliximab). J Clin Rheumatol. 2005; 11:119-20.

35. Mancini G, Erario L, Gianfreda R, Oliva A, Massetti AP, Mastroianni CM, et al. Tuberculosis and Legionella pneumophila pneumonia in a patient receiving anti-tumour necrosis factor-alpha (antiTNF-alpha) treatment. Clin Microbiol Infect. 2007; 13:1036-7.

36. Renaud C, Ovetchkine P, Bortolozzi P, et al. Fatal group A streptococcus purpura fulminas in a child receiving TNF $\alpha$ blockers. Eur J Pediatr 2011; 170:657-60.

37. Morishita K, Petty R, Cairns R. Serious musculoskeletal infections in children receiving anti-tumor necrosis factor-alfa therapy: a case series. Clin Rheumatol 2010; 29:677-81.

38. Galloway JB, Hyrich KL, Mercer LK. Risk of septic arthritis in patients with rheumatoid arthritis and effect of anti-TNF therapy: results from British Society for Rheumatology Biologics Register. Ann Rheum Dis 2011; 70:1810-4.
39. Tsiodras S, Samonis G, Boumpas DT, Kontoyiannis DP. Fungal infections complicating tumor necrosis factor alpha blockade therapy. Mayo Clin Proc 2008; 83:181-94.

40. Hage CA, Bowyer S, Tarvin SE, et al. Recognition, diagnosis, and treatment of histoplasmosis complicating tumor necrosis factor blocker therapy. Clin Infect Dis 2010; 50:85-92.

41. Kaur N, Mahl TC. Pneumocystis jiroveci (carinii) pneumonia after infliximab therapy: a review of 84 cases. Dig Dis Sci 2007; 52:1481-4.

42. Harigai M, Koike R, Miyasaka N. Pneumocystis pneumonia associated with infliximab in Japan. Pneumocystis Pneumonia under Anti-Tumor Necrosis Factor Therapy (PAT) Study Group. N Engl J Med 2007; 357:1874-83.

43. Kling M C, Larian A, Scordi-Bello I, et al. Fatal Influenza $\mathrm{A}(\mathrm{H} 1 \mathrm{~N} 1)$ Respiratory tract infection in a patient having psoriasis treated with Infliximab. Arch Dermatol 2010; 146:651-4.

44. Smitten AL, Choi HK, Hochberg MCT, et al. The risk of herpes zoster in patients with rheumatoid arthritis in the United States and the United Kingdom. Arthritis Rheum 2007; 57:1431-62.

45. Bradford RD, Pettit AC, Wright PW, et al. Herpes simplex encephalitis during treatment with tumor necrosis factor-alpha inhibitors. Clin Infect Dis 2009;49:924-32.

46. Baroco AL and Oldfiel ED. Gastrointestinal Cytomegalovirus Disease in Immunocompromised Patient. Current Gastroenterology Reports 2008, 10:409-16.

47. Helbling D, Breitbach TH, Krause M. Disseminated cytomegalovirus infection in Crohn s disease following infliximab therapy. Eur J Gastroenterol Hepatol 2002; 14:1393-5.

48. Stallmach A, Hagel S, Bruns T. Adverse effects of biologics used for treating IBD. Best Pract Res Clin Gastroenterol.2010; 24:167-82.

49. D'Ovidio V, Vernia P, Gentile G, et al. Cytomegalovirus infection in inflammatory bowel disease patients undergoing anti-TNF $\alpha$ therapy. J Clin Virol 2008:43,180-3.

50. Nath R, Mant C, Luxton J, et al. High risk of human papiloma virus type 16 infections and development of cervical aquamous intraepithelial lesions in systemic lupus erythematosus patients. Arthritis Rheum 2007; 57:619-25.

51. Natural history of cervical human papillomavirus infection among women with systemic lupus ery the- 
matosus. Ann Rheum Dis 2009; 68(suppl3):128-34.

52. Brunasso AM, Puntoni M, Gulia A, Massone C. Safety of anti-tumour necrosis factor agents in patients with chronic hepatitis $\mathrm{C}$ infection: a systematic review. Rheumatology 2011; 50:1700-08.

53. Perez-Alvarez Roberto, Diaz-Lagares Cándido, Garcia-Hernadez Francisco, et al. Hepatitisb B virus Reactivation in patients receiving tumor necrosis factor (TNF)-Targeted Therapy. Medicine 2011; 90:359-71.

54. Kaur PP, Chan VC, Berney SN. Successful etanercept use in an HIV positive patient with rheumatoid arthritis. J Clin Rheumatol 2007; 13:79-80.

55. Cepeda EJ, Williams FM, Ishimori ML, et al. The use of anti-tumour necrosis factor therapy in HIVpositive individuals with rheumatic disease. Ann Rheum Dis 2008; 67:710-2.

56. Kremer JM, Genant HK, Moreland LW, et al. Effects of abatacept in patients with methotrexateresistant active rheumatoid arthritis: a randomized trial. Ann Intern Med 2006; 144:865-76.

57. Weinblatt M, Combe B, Covucci A, et al. Safety of the selective costimulation modulator abatacept in rheumatoid arthritis patients receiving background biologic and nonbiologic disease-modifying antirheumatic drugs: a one-year randomized, placebo-controlled study. Arthritis Rheum 2006; 54:2807-22.

58. Weinblatt M, Schiff M, Goldman A, et al. Selective costimulation modulation using abatacept in patients with active rheumatoid arthritis while receiving etanercept: a randomised clinical trial. Ann Rheum Dis 2007; 66:228-32.

59. Genovese MC, Becker JC, Schiff M, et al. Abatacept for rheumatoid arthritis refractory to tumor necrosis factor alpha inhibition $\mathrm{N}$ Engl J Med 2005;353:1114-18.

60. Salliot C, Dougados M, Gossec L. Risk of serious infections during rituximab, abatacept and anakinra treatments for rheumatoid arthritis: metaanalyses of randomised placebo-controlled trials. Ann Rheum Dis 2009; 68:25-33.

61. Emery P, Keystone E, Tomy HP, et al. IL 6 receptor inhibition with tocilizumab improves treatment outcomes in patients with rheumatoid arthritis refractory to anti-tumour necrosis factor biological. Result from a 24-week multicentre randomized placebo-control trial. Ann Rheum Dis 2008; 67:1516-23.

62. Clifford DB, DeLuca A, Simpson DM, et
al.Natalizumab-asociated progressive multifocal leukoencephalopathy in patients with multiple sclerosis: lessons from 28 cases. Lancet Neurol 2010; 9:438-46.

63. Sorensen PS, Bertolotto A, Edan G, et al. Risk stratification for progressive multifocal leukoencephalopathy in patients treated with natalizumab. Mult SclerJ 2012; 18:143-52.

64. Keown P, Balshaw R; Khorasheh S, et al. Metaanalysis of Basiliximab in renal transplantation. Bio Drugs 2003; 17:271-84.

65. Keown P, Balshaw R; Khorasheh S, et al. Metaanalysis of Basiliximab in renal transplantation Bio Drugs 2003; 17:271-7.

66. Mattei MF, Redonnet M, Gandijbakhch I, et al. Lower risk of infectious deaths in cardiac transplant patients reciving basiliximab versus anti-thymocyte globulin as induction therapy. J Heart Lung Transplant 2007; 26:693-96.

67. Keown P, Balshaw R, Khorasheh S, et al. Metaanalysis of basiliximab for immunoprophylaxis in renal transplantation. BioDrugs 2003; 17:271-80.

68. Przepiorka D, Kernan NA, Ippoliti C, et al. Daclizumab, a humanized anti-interleukin-2 receptor alpha chain antibody, for treatment of acute graftversus-host disease. Blood 2000; 95:83-93.

69. Perales MA, Ishill N, Lomazow WA, et al. Longterm follow-up of patients treated with daclizumab for steroid-refractory acute graft-vs-host disease. Bone Marrow Transplant 2007; 40:481-4.

70. Przepiorka D, Kernan NA, Ippoliti C, et al. Daclizumab, a humanized anti-interleukin- 2 receptor alpha chain antibody, for treatment of acute graftversus-host disease. Blood 2000; 95:83-89.

71. Sievers EL, Larson RA, Stadimauer EA, et al. Efficacy and safety of Gemtuzumab ozagamicin in patients whith CD33-positive acute mieloide leukemia in first relapse. J Clin Oncol 2001:19:3244-55.

72. Martin SI, Marty FM, Fiumara K, et al. Infectious complications associated with alemtuzumab use for lymphoproliferative disorders. Clin Infect Dis 2006; 43:16-29.

73. Peleg AY, Husain S, Kwak EJ, et al. Opportunistic infections in 547 organ transplant recipients receiving alemtuzumab, a humanized monoclonal CD-52 antibody. Clin Infect Dis 2007; 44:204-10.

74. Saadeh CE, Srkalovic G. Mycobacterium avium complex infection after alemtuzumab therapy for chronic lymphocytic leukemia. Pharmacotherapy 2008; 28:281-90. 
75. Chae YS, Sohn SK, Kim JG, et al. Impact of alemtuzumab as conditioning regimen component on transplantation outcomes in case of CMV-seropositive recipients and donors. Am J Hematol 2008; 83:649-52.

76. Chakrabarti S, Mackinnon S, Chopra R, et al. High incidence of cytomegalovirus infection after nonmyeloablative stem cell transplantation: potential role of Campath-1H in delaying immune reconstitution. Blood 2002; 99:4357-62.

77. Laurenti L, Piccioni P, Cattani P, et al. Cytomegalovirus reactivation during alemtuzumab therapy for chronic lymphocytic leukemia: incidence and treatment with oral ganciclovir. Haematologica 2004; 89:1248-55.

78. O’Brien S, Ravandi F, Riehl T, et al. Valganciclovir prevents cytomegalovirus reactivation in patients receiving alemtuzumab-based therapy. Blood 2008; 111:1816-19.

79. Chakrabarti S, Avivi I, Mackinnon S, et al. Respiratory virus infections in transplant recipients after reduced-intensity conditioning with Campath-1H: high incidence but low mortality. Br J Haematol 2002; 119:1125-34.

80. Byrd JC, Rai K, Peterson BL, et al. Addition of rituximab to fludarabine may prolong progressionfree survival and overall survival in patients with previously untreated chronic lymphocytic leukemia: an updated retrospective comparative analysis of CALGB 9712 and CALGB 9011. Blood 2005; 105:49-53.

81. Rafailidis PI, Kakisi OK, Vardakas K, et al. Infectious complications of monoclonal antibodies used in cancer therapy: a systematic review of the evidence from randomized controlled trials. Cancer 2007; 109:2182-92.

82. Aksoy S, Dizdar O, Hayran M, et al. Infectious complications of rituximab in patients with lymphoma during maintenance therapy: a systematic review and meta-analysis. Leuk Lymphoma 2009; 50:357-66.

83. Vidal L, Gafter-Gvili A, Leibovici L, et al. Rituximab maintenance for the treatment of patients with follicular lymphoma: systematic review and metaanalysis of randomized trials. J Natl Cancer Inst 2009; 101:248-50.

84. Greenwald MW, Shergy WJ, Kaine JL, et al. Evaluation of the safety of Rituximab in combination with a Tumor Necrosis Factor Inhibitor and Metotrexate in patients with active Rheumatoid Arthritis. Ar- thritis and Rheumat. 2011; 63:622-32.

85. Genovese MC, Breedveld FC, Emery P, et al. Safety of biological therapies following Rituximab treatment in Rheumatoid Arthritis patients. Ann Rheum Dis 2009; 68:1894-7.

86. Keystone E, Fleischmann R, Emery P, et al. Safety and efficacy of additional courses of Rituximab in patients with active Rheumatoid Arthritis. Arthritis and Rheumatol. 2011; 56:3896-08.

87. I-Cheng Lee, Huang YH, Chu ChJ, et al. Hepatitis $\mathrm{B}$ virus reactivation after 23 months of Rituximab - based chemotherapy in an HBsAg-negative, AntiHBs-positive patient with follicular Lymphoma. J Chin Med Assoc. 2010; 73:156-60.

88. Mastroianni CM, Lichtner M, Citon R, et al. Current trends in management of hepatitis $\mathrm{B}$ virus reactivation in the biologic therapy era. World J Gastroenterol. 2011; 17:3881-7.

89. Carson KR, Evens AM, Richey EA, et al. Progressive multifocal leukoencephalopathy after rituximab therapy in HIV negative patients: a report of $57 \mathrm{ca}-$ ses from the Research on Adverse Drugs Events and Reports project. Blood 2009; 113:4834-40.

90. Venhuizen AC, Hustinx WN, van Houte AJ, et al. Three cases of Pneumocystis jirovecii pneumonia (PCP) during first-line treatment with rituximab in combination with CHOP-14 for aggressive B-cell non-Hodgkin's lymphoma. Eur J Haematol 2008; 80:275-7.

91. Green H, Paul M, Vidal L, et al. Prophylaxis of Pneumocystis Pneumonia in Immunocompromised Non-HIV-Infected Patients: Systematic Review and Meta-analysis of Randomized Controlled Trials. Mayo Clin Proceed. 2007; 82:1052-9.

92. Worth LJ, Dooley MJ, Seymour JF, et al. An analysis of the utilization of chemoprophylaxis against Pneumocystis jirovecci pneumonia in patients with malignancy receiving corticosteroid therapy at caner hospital. Br J of Cancer. 2005; 92(5):867-72.

93. Viget N, Vernier-Massouiler G Salomon D, et al. Oportunistic infections in patients with inflamatory bowel disease: prevention and diagnosis. Gut 2008; 57:549-58.

94. den Broeder AA, Creemers MC, Fransen J, et al. Risk factors for surgical site infections and other complications in elective surgery in patients with rheumatoid arthritis with special attention for antitumor necrosis factor: a large retrospective study.J Rheumatol 2007; 34:689-95.

95. Ferrante M, D'Hoore A, Vermeire S, et al Corti- 
costeroids but not infliximab increase short-term postoperative infectious complications in patients with ulcerative colitis. Inflamm Bowel Dis 2009; 15:1062-70.

96. Actualización de recomendaciones sobre vacunas. Comisión de Vacunas 2008. Comisión directiva de SADI y comisión de vacunas. Kroger AT, Atkinson WL, Marcuse EK, et al.

97. Kroger AT, Atkinson WL, Marcuse EK, et al. General recommendations on immunization: recommendations of the Advisory Committee on Immunization Practices (ACIP). MMWR Recomm Rep. 2006; 55(RR-15):1-48.

98. Guarnizo Zuccardi P, Eraso Garnica R, Ramirez Gomez L. Inmunización en pacientes con enfermedades reumáticas. Revista Colombiana de Reumatología 2006; 13:65-75.

99. Deane K Vaccines in Adult Patients With Rheumatic Disease: Balancing Risks and Benefits Medscape Rheumatology 2009.

100.Weber D, Rutala W. Immunization of immunocompromised persons. Immunol Allergy Clin North Am 2003; 23:605-34.

101.Fiore AE, Uyeki TM, Broder K, et al. Prevention and control of influenza with vaccines: recommendations of the Advisory Committee on Immunization Practices (ACIP), 2010.Centers for Disease Control and Prevention (CDC).MMWR Recomm Rep. 2010 Aug 6; 59(RR-8):1-62.

102.American College of Rheumatology Hotline. Herpes zoster Shingles vaccine guidelines for immunosuppressed patients. Aug 1, 2008.

103. Kavanaugh A. Infection prophylaxis in antirheumatic therapy: emphasis on vaccination Curr Opin Rheumatol 2009, 21:419-24.

104.Reimold ., Palmer B. Viruses and arthritis: new challenges in diagnosis, therapy and immunization. Am J Med Sci 2010; 339:549-56.

105.Conti F, Rezai S, Valesini G. Vaccination and autoimmune rheumatic diseases. Autoimmun Rev 2008; 5:124-8.

106.Agmon-Levin N, Paz Z, Israeli I and Shoenfeld Y. Vaccines and autoimmunity Nature Rev Rheum Nov 2009; 5,5:648-52.

107.Assen SV, Agmon Levin N, Elkayan O, et al. EULAR recommendations for vaccination in adult patients with autoimmune inflammatory rheumatic diseases Ann Rheum Dis 2011; 70:414-22.

108. Assen SV, Elkayan O, Agmon Levin N, et al. Vaccination in adult patients with auto-immune inflammatory rheumatic diseases: A systematic literature review for the European League Against Rheumatism evidence- based recommendations for vaccinations in adult patient with auto-immune inflammatory rheumatic diseases. Autoimmun Rev 2011; 10:341-52.

109.Winthrop KL. Infections and biologic therapy in rheumatoid arthritis. Rheum Dis Clin N Am 2012; 38:727-45.

110.Genovese MC, Cohen S, Moreland L, et al. Combination therapy with etanercept and anakinra in the treatment of patients with rheumatoid arthritis who have been treated unsuccessfully with metotrexate. Arthritis Rheum 2004; 50:1412-9.

111.Furst DE. The risk of infections with biologic therapies for rheumatoid arthritis. Semin Arthritis Rheum 2010; 39:327-46.

112.Rubin LG, Levin MJ, Ljungman P, et al. 2013 IDSA clinical practice guideline for vaccination of the immunocompromised host. Clin Infect Dis 2014; 58:309-18.

113.Rahier JF, Moutschen M, Van Gompei A, et al. Vaccinations in patients with immune-mediated inflammatory diseases. Rheumatology 2010; 49:1815-27.

114.van Assen S, Elkayam O, Agmon-Levin N, et al. Vaccination in adult patients with auto-immune inflammatory rheumatic diseases: A systematic literature review for the European League Against Rheumatism evidence-based recommendations for vaccination in adult patient with auto-immune inflammatory rheumatic diseases. Autoimmun Rev 2011; 10:341-52.

115.Komano Y, Tanaka M, Nanki T, et al. Incidence and risk factors for serious infection in patients with rheumatoid arthritis treated with tumor necrosis factor inhibitors: a report from the Registry of Japanese Rheumatoid Arthritis Patients for Longterm Safety. J Rheumatol 2011; 38:1258-64.

116.Atzeni F, Sarzi-Puttini P, Botsios C, et al. Longterm anti-TNF therapy and the risk of serious infections in a cohort of patients with rheumatoid arthritis: comparison of adalimumab, etanercept and infliximab in the GISEA registry. Autoimmun Rev 2012; 12:225-9. 